\title{
Da longevidade à velhice
}

\section{Fernanda dos Reis Rougemont*}

\begin{abstract}
Resumo: Este artigo tem o objetivo de analisar a percepção do envelhecimento e da velhice no contexto do aumento da expectativa de vida. Por meio da análise de 1.615 questionários aplicados na cidade do Rio de Janeiro, realiza-se uma comparação entre faixas etárias destacando o que consideram fatores positivos e negativos de envelhecer, contrapondo-os às aspirações do envelhecimento ideal. A análise foca as modificações nas representações e na vivência desse processo e busca compreender os efeitos da longevidade na vida social, bem como discutir o significado de uma vida mais longa e sua caracterização na sociedade brasileira, especialmente no Rio de Janeiro.
\end{abstract}

Palavras-chave: envelhecimento, longevidade, corpo, geração, experiência.

\section{Introdução}

O Brasil está envelhecendo. Essa afirmação diz respeito a uma mudança no perfil da sociedade brasileira, com o crescimento da população com mais de 60 anos, acompanhando uma tendência mundial. Segundo dados do Censo de 2010 do IBGE, há cerca de 19 milhões de brasileiros nessa faixa etária, o que corresponde a mais de $10 \%$ da população. A estimativa é de que até 2025 existam mais de 32 milhões de idosos no país. A expectativa de vida atual do brasileiro é de 73 anos, sendo 77 anos para as mulheres e 69,9 anos para os homens. A ampliação do tempo de vida deve-se, principalmente, aos avanços da medicina e da tecnologia, que criaram novos meios para os cuidados com a saúde e com a qualidade de vida.

Tendo em vista as transformações da composição etária da sociedade brasileira, este artigo, que faz parte da pesquisa Corpo, Envelhecimento e Felicidade, busca, por meio da análise de discursos, observar a percepção que os pesquisados possuem do envelhecimento e da velhice. A proposta é analisar os conflitos, os problemas e as perspectivas que as novas condições de vida promoveram e os possíveis desdobramentos da longevidade na vida social. Valendo-se da caracterização do que os pesquisados concebem como velhice e juventude, pretende-se compreender o que é esperado do processo de envelhecimento e como a atual configuração populacional influencia a relação entre gerações.

\footnotetext{
${ }^{*}$ Graduada em Ciências Sociais - UFRJ.
} 
Para tais objetivos, foram utilizados três questionários aplicados entre os anos de 2007 e 2010 em 1.615 pesquisados de 18 a 97 anos, na cidade do Rio de Janeiro. Para a comparação entre a juventude e a velhice são analisadas as respostas dadas às perguntas "quando uma pessoa pode ser considerada velha?", "quando uma pessoa começa a envelhecer?", "qual o melhor de envelhecer"? e "o que você inveja em um jovem? Por quê?". Para a compreensão do que é o envelhecimento ideal é considerada a pergunta "dê um exemplo de uma pessoa famosa/pública que você acha que envelheceu bem. Explique a sua escolha.". A análise tem como foco a comparação entre faixas etárias. Para isso, os pesquisados foram divididos em três grupos etários: até 39 anos, 40 a 59 anos e 60 anos ou mais. Os grupos foram delimitados após uma análise prévia ${ }^{1}$ que observou similaridades que justificam seu agrupamento.

Acredita-se que essa pesquisa ajudará a perceber de que forma a reconfiguração etária da população pode interferir na convivência entre pessoas de diferentes faixas de idade, reordenando as fronteiras entre a juventude e a velhice.

\section{Decadência física e ganhos intelectuais}

Myriam Lins de Barros (2004) destaca que a construção social da velhice é própria da modernidade e ocorre no contexto da consolidação da ideologia individualista. Tal construção foi acompanhada da divisão e institucionalização de diferentes momentos do curso da vida: a infância, a juventude e a velhice. Para a autora, a velhice possui múltiplos significados culturais, de acordo com os contextos sociais específicos aos quais os indivíduos pertencem. Além disso, como afirma Alda Britto da Motta (2006), as idades, enquanto elementos fundamentais na organização e na cultura da sociedade, participam de sua dinâmica, passando por um processo de construção e desconstrução e modificando seus significados.

\footnotetext{
${ }^{1}$ Inicialmente os pesquisados foram divididos em faixas de 10 em 10 anos (exceto a de 18 a 29 anos). As respostas de cada pergunta foram analisadas e classificadas em temas, categorias e subcategorias e, em seguida, foram feitas porcentagens. Observaram-se similaridades entre as faixas de idade que foram aqui agrupadas. Contudo, a análise pormenorizada permite outras formas de agrupamento quando necessário e possibilita destacar algumas especificidades.
} 
Dentre os diferentes aspectos do envelhecimento tratados pelos pesquisados, destaca-se uma diferenciação entre duas formas de envelhecimento: o físico e o não físico. $O$ envelhecimento biológico é visto como algo inevitável e as transformações decorrentes dele são vistas predominantemente como inconvenientes. Dentre as principais mudanças no corpo estão as doenças, as limitações físicas, as rugas e os cabelos brancos.

Os fatores positivos que designam o envelhecimento são referentes ao intelecto. Visto como trajetória de vida, o envelhecimento é experiência, conhecimento adquirido por tudo que foi vivenciado ao longo da vida. Desse modo, o acúmulo de conhecimento será um elemento positivo na velhice, pois trará a sabedoria. A maturidade, por sua vez, é relacionada tanto à experiência de vida e à passagem de uma fase da vida à outra quanto ao desenvolvimento do organismo. Apesar das perdas físicas, envelhecer teria como recompensa ganhos intelectuais: a experiência, a sabedoria e a maturidade.

O discurso dos pesquisados a respeito do que consideram ser o melhor de envelhecer sugere que tais ganhos intelectuais são os aspectos mais valorizados no envelhecimento. A experiência foi o tema mais citado pelos pesquisados em todas as faixas etárias, representando 68\% das respostas de 593 pesquisados. Sabedoria com $20,5 \%$, conhecimento com $26,3 \%$ e maturidade com $16,3 \%$ das respostas confirmam o aprendizado pessoal como a principal conquista do envelhecimento. Principalmente nas faixas até 39 anos e de 49 a 59 anos, os pesquisados afirmam que a experiência adquirida ao longo da vida é o melhor de envelhecer porque auxilia as pessoas a lidar com as situações cotidianas, uma forma de conhecimento prático. Esse conhecimento permite que se reconheçam situações anteriormente vivenciadas e que se possa agir com mais segurança e evitar erros ao tomar decisões e lidar com situações adversas. Há também a utilização da experiência em relação ao outro, que é vista como uma prerrogativa, indicando que seria por meio do conhecimento, dessa sabedoria de vida, que os mais velhos teriam uma posição favorável em relação aos mais jovens, como aponta um pesquisado: "você pode dar esporro nos outros com o respaldo das maravilhas da experiência de vida" (Homem, 20 anos). 
Já a faixa de 60 anos ou mais destaca apenas a experiência de vida, que corresponde a $58,8 \%$ das respostas de 62 pesquisados. Para os pesquisados mais velhos, além da experiência, são fatores positivos ter netos (37\%), filhos $(34,4 \%)$ e as conquistas em geral $(11,9 \%)$.

\section{Envelhecer e ficar velho}

Os recentes dados populacionais no Brasil e no mundo que mostram a evidente ampliação dos anos de vida apontam para uma questão crucial no entendimento dos efeitos que tal conquista tem do ponto de vista social. Como afirma a antropóloga Guita Debert (2006), existem diferentes formas de periodização da vida e as categorias de idade bem como o caráter dos grupos etários são vias importantes para se pensar a produção e reprodução social. A velhice possui duas dimensões, a social e a biológica, na qual a primeira está relacionada à segunda, uma vez que consiste em diferentes formas de perceber e vivenciar o processo biológico de envelhecimento. É pertinente, portanto, analisar as fronteiras etárias que realizam uma divisão no todo social e a presente configuração das relações de divisão de poder e prestígio, direitos e deveres na população diante das mudanças biológicas do ciclo de vida.

Como mostra Clarice Peixoto (2004), a representação da pessoa envelhecida passou por diversas modificações ao longo do tempo. As mudanças sociais, oriundas principalmente do advento da aposentadoria, demandavam políticas sociais direcionadas à velhice e suscitavam a criação de novas categorias de classificação condizentes com a nova condição moral, bem como a construção ética do objeto "velho".

Tendo o contexto francês como referência, a autora destaca as condições miseráveis da velhice trabalhadora no século XIX. Metade das pessoas com mais de 60 anos não possuía renda e dependia dos filhos ou de instituição de assistência pública. 0 problema da velhice era referente à situação das pessoas que não podiam assegurar seu futuro financeiramente. A noção de "velho" é, portanto, fortemente associada à decadência e confundida com a incapacidade para o trabalho, categorizando indivíduos idosos e pobres. 
No contexto brasileiro, o termo "velho" e sua conotação negativa seguem um processo similar ao caso francês. "Velho" designa as pessoas de mais idade, que pertencem às classes populares e que apresentam sinais de envelhecimento e declínio físico mais nitidamente. Remete, portanto, à decadência.

Ao definirem o que consideram ser uma pessoa "velha", os pesquisados citaram principalmente mudanças físicas e comportamentos vistos de forma negativa. 0 velho é aquele cuja decadência física é perceptível, que tem rugas e cabelos brancos, limitações físicas, a mente não acompanha mais o corpo. Tais transformações são inevitáveis e são concebidas como uma manifestação do desgaste natural do organismo. Por outro lado, a pessoa velha é definida por uma gama de características que se referem ao seu comportamento e este, na visão dos pesquisados, pode ser mais controlado pelas pessoas, embora muitas vezes a condição de velho seja imposta pelas situações. Nesse sentido, ser velho é ser inútil, ranzinza, acomodado, reclamar de tudo, não ter mais vontade de viver, deixar de sonhar, sentir-se incapaz, sentir-se velho. Entre as respostas de 690 pesquisados, 95\% citam o "estado de espírito"; 49\%, a decadência física; 27\%, o comportamento adotado pelas pessoas.

A respeito de quando uma pessoa começa a envelhecer, foi recorrente na faixa etária mais nova a ideia de que tal processo se inicia no nascimento, representando 41,5\% das citações de 326 pesquisados. A definição do momento em que se chega à velhice dependeria principalmente do comportamento. Uma pessoa começa a envelhecer quando ela própria se acha velha (28\%) e quando ela perde a vontade de viver (20\%). As limitações físicas vêm em seguida com 19\%. Já para as faixas etárias mais velhas são as limitações físicas o principal sinal do envelhecimento. Os 205 pesquisados da faixa de 40 a 59 anos representam $28 \%$ das respostas. A sequência com perder a vontade de viver (21\%), a própria pessoa achar-se velha (21\%) e desde o nascimento (12\%) promove uma inversão na importância dos fatores em relação à faixa anterior. A faixa mais velha, de 60 anos ou mais, dá continuidade à valorização de aspectos físicos do envelhecimento. As limitações físicas foram citadas em 74,5\% das respostas de 62 pesquisados, com destaque para o aparecimento de doenças. 
As percepções do envelhecimento apresentadas pelas faixas etárias podem indicar uma diferença entre projeção e vivência da velhice, bem como diferenças nos problemas que esperam enfrentar. Uma vez que os pesquisados mais novos nasceram em uma época em que se vive mais intensamente, a perspectiva é de um envelhecimento controlado e mais lento.

É pertinente observar que a experiência, a maturidade e a sabedoria são utilizadas pelos pesquisados como um contraponto à velhice e seriam uma forma de evitar que uma pessoa se torne velha. Essas categorias remetem a um conhecimento que só pode ser adquirido ao longo do tempo e que consiste em uma vantagem em relação aos mais novos. Aquele que é experiente, sábio e maduro envelheceu, mas não se tornou "velho". Envelhecer é biológico, ficar velho depende da pessoa, de seu comportamento e de saber usar a experiência de vida para não se tornar um estereótipo de velho, dando significado pessoal à sua trajetória de vida.

A velhice pode ser percebida nesse discurso como uma condição de vida, com elementos variantes que dependem das condutas adotadas pelos indivíduos. Há, contudo, uma contradição, visto que a decadência do corpo é tida como uma mudança inevitável e determinante da velhice e seria o maior entrave para uma vida longa e ativa. Do mesmo modo, as relações podem impor o status de velho, independentemente de a pessoa se sentir jovem.

\section{O valor da experiência}

O envelhecimento associado à experiência faz parte da formação pessoal e por isso representa um ganho. 0 conhecimento que só pode ser conquistado ao longo dos anos de vida seria, portanto, uma vantagem a ser valorizada. Como sugere a resposta de um pesquisado, o melhor de envelhecer seriam "os ganhos sociais: status, chefia”. Segundo Pierre Bourdieu (1983), tradicionalmente há uma correlação entre sabedoria e poder. Uma vez que esse conhecimento seria proporcional à idade, a valorização da experiência, da sabedoria e da maturidade nos discursos é uma referência àquilo que garante um lugar específico para os velhos. Se, como afirma Bourdieu, a divisão entre jovens e velhos concede aos jovens funções e atividades fazendo com que, em contrapartida, deixem outras exclusivamente para os 
mais velhos, compreender os limites e os critérios que delimitam as duas classificações é imprescindível para compreender a dinâmica entre as gerações.

Ao responderem o que invejam em um jovem, os 358 pesquisados a partir de 40 anos utilizaram características que indicam determinados aspectos associados à juventude. 0 jovem é aquele que pode agir sem pensar, não tem responsabilidades, tem liberdade para divertir-se, para agir impulsivamente. É ousado e inconsequente, despreocupado. 0 jovem dispõe da força e do vigor físico, da saúde, da pele lisa e bonita e, assim, detém a beleza. Principalmente para os pesquisados de 40 a 59 anos, o jovem tem tranquilidade em relação ao futuro, pois tem toda a vida pela frente. A juventude possui como vantagem a sensação de início, em contraposição ao fim que sugere a velhice.

É possível associar a juventude à atividade, ao movimento, ao que ainda será formado, o novo. Já a velhice está predominantemente associada ao passado, ao que já foi realizado e representa uma redução dessa atividade. Essa noção pode ser percebida na fala de um pesquisado de 74 anos, que ao responder o que inveja em um jovem diz: "ah, na juventude, a alegria, tem aquela esperança na vida, planejamentos. Eu, por exemplo, o que eu vou fazer? Eu tenho apartamento, 20 imóveis. Quero mais o quê?".

São recorrentes os temperamentos tranquilo, sereno e calmo para caracterizar a velhice. Esta seria uma fase em que há redução do ritmo de vida, na qual as pessoas buscariam atividades mais tranquilas, afastando-se principalmente das obrigações do trabalho. A aposentadoria é um dos principais marcos do envelhecimento, pois seria a concretização dessa redução do ritmo de vida e a saída da vida produtiva, dando lugar aos mais jovens na produção dos bens necessários a sociedade e sua renovação. A aposentadoria é vista de forma positiva, como um merecimento por tudo que os indivíduos fizeram pela sociedade. Por outro lado, ela marca a entrada em uma nova fase, afastada dos centros de maior atividade e socialmente mais importantes. Nesse sentido, o campo do trabalho é crucial para se analisar as mudanças na sociedade, uma vez que representam o legado da geração anterior e a substituição pela geração sucessora.

0 processo de sucessão dos velhos pelos jovens no mercado de trabalho é mostrado por Deborah Stucchi (2006) em sua análise sobre os Programas de Pre- 
paração para Aposentadoria (PPA). Como destaca a pesquisadora, a valorização dos empregados selecionados é proporcional à sua juventude, fator crucial no recrutamento de novos trabalhadores. A idade avançada representa risco de incapacidade para o trabalho. Stucchi destaca também que a aposentadoria é marcada pela saída do mundo do trabalho e entrada no mundo doméstico e vivenciada de forma conflitante como a passagem do mundo de poder para outro mundo em que o poder está na mão de outros. Diante da impossibilidade de definir o momento exato da passagem da produtividade para a improdutividade, a ideia da préaposentadoria, que constitui esses programas, busca solucionar esse impasse transferindo para os trabalhadores a responsabilidade de decidir o momento de se aposentar. Transforma-se, assim, o direito da aposentadoria em um dever.

\section{A velhice ideal}

Considera-se que as pessoas públicas, enquanto ídolos, são personagens emblemáticas que de alguma forma venceram obstáculos que pareciam intransponíveis. Em uma sociedade midiatizada, a indústria cultural é responsável pela criação de novos mitos e a comunicação de massa, por sua vez, é o espaço de produção de discursos sociais, como afirmam Helal e Coelho (1996, p. 79-88). Para os autores, ao falarmos de narrativas sociais estamos nos referindo a rituais, tal como observado por Clifford Geertz, enquanto uma história que contamos para nós sobre nós mesmos. Essas histórias mobilizam a população sob a forma de sucessos ou escândalos. Desse modo, as trajetórias dessas personalidades públicas seriam editadas de forma a contar a história de seu público. Contamos suas histórias para falarmos de nós mesmos.

Aqui buscamos analisar os exemplos de pessoas famosas que, para os pesquisados, envelheceram bem, admitindo que essas pessoas são como imagens nas quais a comunidade projeta suas aspirações. Tendo visto os discursos a respeito de diferentes fases e aspectos do processo de envelhecimento, as pessoas públicas citadas permitem observar de modo objetivo o que é valorizado e o que é desvalorizado no envelhecimento e na velhice, uma vez que elas refletem os anseios do 
ideal de envelhecimento para além de um discurso abstrato ou projeção por serem referências concretas.

De um total de 967 pesquisados, os exemplos femininos de bom envelhecimento mais citados pelos pesquisados foram: Dercy Gonçalves (20\%), Fernanda Montenegro (19\%), Madonna (7\%), Glória Menezes (6\%) e Hebe Camargo (6,2\%). Entre os exemplos masculinos, os mais citados foram: Oscar Niemeyer (17\%), Silvio Santos (9\%), Tarcísio Meira (6\%), Chico Buarque (2\%) e Caetano Veloso $(1,2 \%)$.

As justificativas dadas para os exemplos citados são predominantemente relacionadas ao corpo, à vida profissional e ao estilo de vida. Envelhecer bem é estar em forma, não aparentar a idade que tem, continuar bonito ou ficar mais bonito, ter saúde, vitalidade, energia e disposição, manter-se ativo, produtivo, trabalhando tão bem quanto antes ou melhor. Madonna pode ser considerada o principal exemplo para a faixa etária mais nova, sendo majoritariamente citada por pesquisados com idades até 39 anos. A fala de uma pesquisada dessa faixa sintetiza o discurso predominante sobre o bom envelhecimento: "Madonna. Ela parece ser muito mais jovem do que é. Ou seja, o que invejo nela é a capacidade de permanecer com todas as características que julgo existentes principalmente na juventude: beleza, liberdade, descontração, sexualidade etc. Eu, imersa em todo meu preconceito, não consigo (nem quero) imaginar a sexualidade de velhos".

Para envelhecer bem é necessário não aparentar ter envelhecido e não deixar que o envelhecimento altere o ritmo de vida. Os exemplos são pessoas que envelheceram, e, por isso, foram citadas, mas são destacadas porque têm aparência, comportamento e atividade relacionados à juventude. As características do envelhecimento ideal são contraditórias aos aspectos citados como o melhor de envelhecer. Se a aposentadoria, a tranquilidade, o tempo livre, a família constituída, as lembranças e, principalmente, a experiência, a sabedoria e a maturidade aparecem no discurso como as vantagens que a velhice pode trazer, é a manutenção, ou extensão, das características que se tinha na juventude que garante um bom envelhecimento. Deve-se continuar a trabalhar, ser ativo e retardar ao máximo a decadência física. 
Há, ainda, uma importante oposição na definição de um bom envelhecimento: o natural e o artificial. Principalmente quando se trata da aparência, têm vantagem aqueles que envelhecerem sem precisar recorrer a muitos artifícios. Embora atualmente estejam à disposição centenas de técnicas e procedimentos para atenuar sinais físicos de envelhecimento, são os cuidados em longo prazo, que refletem um estilo de vida, os mais apreciados. Madonna, que representa o ideal de envelhecimento para os pesquisados mais novos, é uma referência dessa forma de envelhecer. Segundo uma pesquisada, ela envelheceu bem porque "provavelmente são anos e anos de boa alimentação e carga pesada de preparo físico, mas ela está com 50 anos e está no auge. Além de tratamentos estéticos, a questão financeira também ajuda na conservação da juventude." Como a própria resposta indica, esse estilo de vida tem um custo, além de necessitar de um planejamento e controle sobre o próprio corpo, o que limitaria o número de pessoas com condições de possuir esse modo de viver e alcançar esse envelhecimento.

Exemplo mais recorrente entre os pesquisados de 18 a 39 anos, Dercy Gonçalves representa um envelhecimento natural, porém sem limitações e distinto de outras pessoas de sua época. Como afirmam duas pesquisadas "ela aproveitou a vida como quis e nunca deixou a idade realmente chegar. Ela sempre foi muito verdadeira" e "soube viver e envelhecer naturalmente".

Fernanda Montenegro é o exemplo mais citado pelos pesquisados a partir de 40 anos. Ela representa um ideal de envelhecimento ativo, profissionalmente bem-sucedido, com experiência de vida e muitas realizações. Fisicamente não aparenta a idade que tem, continua bonita, bem disposta, saudável e não precisou recorrer a plásticas e meios artificias para conseguir envelhecer com boa aparência. Sua citação manifesta o conflito entre dois fatores que são considerados necessários ao bom envelhecimento pelos pesquisados mais velhos: não negar o envelhecimento, tentando ser alguém mais novo, por um lado, e manter a juventude ao longo do envelhecimento, por outro. A resposta de uma pesquisada de 49 anos ilustra esse ideal: "está mais bonita do que anos atrás; é uma pessoa de bem com a vida, não tentou mudar a aparência para parecer mais moça, tem muita dignidade e é tremendamente simpática e educada". 
Observamos a existência de um tênue limite entre a manutenção de características próprias e a necessidade de interferir e controlar o envelhecimento, evitando a manifestação de seus sinais, principalmente fisicamente. 0 excesso de plásticas e intervenções cirúrgicas transforma a pessoa em algo que ela não é; é artificial. Por outro lado, possuir excessos de marcas do envelhecimento contraria o ideal de uma aparência jovem. No comportamento, há que se adequar à sua trajetória de vida e a idade que possui, sem deixar que o envelhecimento reduza suas possibilidades e atividades. Tem-se o desafio de assumir o envelhecimento e sua trajetória de vida sem envelhecer, ao menos no que se refere a um modelo tradicional de envelhecimento, relacionado à decadência e à improdutividade.

Por meio dos discursos, foi possível identificar quais fatores são considerados pelos pesquisados para definir e julgar o que é um bom envelhecimento. Tais fatores apontam questões que estão de acordo com o debate proposto por Featherstone e Hepworth (2000) acerca do papel da ciência e da tecnologia em relação ao envelhecimento e ao curso da vida, na medida em que é desempenhado no sentido de afastar a decadência física e a morte. Opõe-se o envelhecimento mais natural, com a utilização da tecnologia como forma de preservar a vida, e a incorporação da tecnologia ao curso da vida.

\section{A longevidade}

A expectativa de vida atual é um fato que tem provocado novos debates na comunidade científica. Em artigo do final da década de 1980, Kalache, Veras e Ramos (1987) analisaram a diferença na expectativa de vida nos países desenvolvidos e nos chamados "países do terceiro mundo". Estimava-se que, da década de 1960 até 2020, a expectativa de vida nos países em desenvolvimento aumentaria 23 anos, chegando a 68,9 anos. Já nos países desenvolvidos esse aumento seria, comparativamente, muito menor, passando de 69,8 para 77,2 anos. A previsão de estabilização nas taxas de crescimento da expectativa de vida nos países desenvolvidos baseava-se no limite biológico de vida da espécie humana, até então calculado em aproximadamente 120 anos. Estatísticas de 2010 apontam a superação desses números tanto no Brasil, onde o tempo médio de vida chegou a 73,17 anos, se- 
gundo o IBGE, quanto em países como o Japão, com média de 82,7 anos, e Estados Unidos, com média de 79,2 anos, segundo dados da ONU. Os limites da vida humana começam a ser questionados. Jim Oeppen e James Vaupel (2002) afirmam que brevemente viver mais de 100 anos será comum. Os cientistas contestam, ainda, a existência de evidências que apontem um limite para a expectativa de vida humana.

A questão que emerge diz respeito ao caráter dessa vida mais longa e seus efeitos sobre a vivência do processo de envelhecimento no Brasil, especialmente na cidade do Rio de Janeiro. As análises dos discursos indicam que a visão da velhice é predominantemente negativa, mas que há em relação ao envelhecimento, enquanto ciclo, anseios por mudanças, de modo que envelhecer não seja uma redução de possibilidades. Isso fica evidente na tentativa por parte dos pesquisados de relativizar a "chegada" à velhice. Assim, envelhecer é inevitável, mas os pesquisados buscam apontar alternativas para retardar a velhice, principalmente por meio do comportamento pessoal.

Segundo Elias (2001), a atitude em relação à morte e sua imagem nas sociedades contemporâneas não podem ser compreendidas sem que seja feita uma referência à segurança relativa, à previsibilidade da vida humana e à expectativa de vida maior. Ampliar cada vez mais o tempo de vida é uma meta que pode ser observada nos esforços científicos para desvendar o processo de envelhecimento no organismo humano em busca de meios para controlá-lo.

Como mostram Ilka Teixeira e Anita Neri (2008, p. 81-94), há uma busca na sociedade ocidental pelo significado de envelhecimento bem-sucedido. Iniciada na década de 1940, a discussão sobre o conceito ainda não alcançou um consenso. Entretanto, a literatura sobre o assunto sugere alguns aspectos centrais da noção de bom envelhecimento.

Segundo a observação das autoras, os fatores estão predominantemente relacionados à dicotomia sucesso/fracasso, bem como à tendência de responsabilização dos indivíduos pelas condições boas ou ruins de seu envelhecimento com base na estipulação de critérios objetivos. É possível considerar que as características para um bom envelhecimento são referentes à manutenção da saúde, não ter perdas cognitivas e nem ausência de capacidades, participar ativamente na sociedade 
com contatos sociais intensos e assumir atitudes positivas perante a vida. 0 que está em jogo não é somente aumentar os anos de vida, mas a qualidade desses anos, o que implica uma nova percepção do ciclo de vida e de sua periodização.

\section{Considerações finais}

O discurso dos pesquisados indica que o envelhecimento ideal é aquele que mais se afasta da ideia de velho e mais se aproxima da juventude. Embora o desgaste do organismo seja algo inevitável, ser velho não é meramente um resultado do processo, mas uma condição com diversos outros fatores envolvidos, em que as relações com outras pessoas e o comportamento individual perante a vida são determinantes.

Destaca-se nos discursos a subjetivação do processo de envelhecimento com a valorização de fatores individuais, relativos à trajetória pessoal. Tornar-se velho é diferente de envelhecer, pois o envelhecimento biológico pode ser atenuado e tornar-se mais lento, aumentando o período de plena atividade, o que significaria estender a juventude. Atualmente, a comunidade científica tem investido em pesquisas que desvendem o envelhecimento para que assim seja possível reverter o processo. Tanto do ponto de vista estético quanto da saúde, os estudos buscam apontar métodos para retardar o processo ou mesmo evitá-lo. Como indica Mirian Goldenberg (2007), o Brasil é o segundo país com maior índice de plásticas, sendo um dos principais motivos o desejo de apagar as marcas do envelhecimento.

Embora o conceito do bom envelhecimento não esteja definido e seja ressaltado cada vez mais o seu caráter subjetivo, observa-se a existência de um padrão de envelhecimento que evidencia a questão da longevidade; não se limita ao prolongamento da vida, mas diz respeito também à caracterização dessa vida mais longa.

Diante dos fatores apresentados, é pertinente considerar o desajustamento de fronteiras etárias tradicionais. Em uma reflexão sobre a velhice, Norberto Bobbio (1997) compara o lugar dos velhos nas sociedades antigas e nas sociedades modernas. Nas sociedades tradicionais, os velhos eram valorizados principalmente por serem os responsáveis pela transmissão do conhecimento e porque represen- 
tavam a herança cultural da comunidade. Essa função se perderia nas sociedades modernas caracterizadas pelas rápidas transformações e pela facilidade de acesso ao conhecimento. No mundo contemporâneo marcado pela especialização do conhecimento e pelos avanços tecnológicos que tornaram os meios de comunicação mais eficientes e facilitaram o acesso à informação, a sabedoria dos mais velhos perde o papel central na reprodução social. Ainda que os discursos apresentados indiquem que a sabedoria de vida e a experiência ainda são valorizadas como fatores positivos do envelhecimento, deixam de ser elementos necessários à reprodução social e passam a ser um ganho mais individual e que faz parte da formação pessoal, ainda que possa ser um fator de prestígio em contextos específicos.

Bourdieu (1983) destaca o caso de uma sociedade australiana onde a magia de rejuvenescimento praticada por mulheres mais velhas era vista como "diabólica", pois perturbava os limites entre as idades e não se sabia mais quem era jovem e quem era velho. A classificação em "jovem" ou "velho", uma vez que é arbitrária, modifica-se de acordo com os interesses em jogo. Em um contexto no qual se almeja uma população que não envelheça, quais serão os efeitos sobre a sociedade? Certamente a ampliação do tempo de vida e as expectativas em relação a esses anos a mais sugerem mudanças nas relação entre gerações, assim como transformações em diversos setores da vida social. Um exemplo disso é o impacto do envelhecimento da população sobre a previdência social, que tornou a necessidade de adaptações evidentes e recentemente vem provocando mudanças no âmbito institucional. Na França, em 2010, o governo enfrentou protestos pelas mudanças adotadas, principalmente o aumento do tempo de trabalho necessário para se aposentar. As alterações do envelhecimento biológico provocam desajustes em relação às antigas formas de pensar o ciclo de vida, principalmente do ponto de vista da renovação da sociedade. Os direitos e deveres de cada parcela da população passam por uma revisão. De acordo com as evidências, é possível afirmar que a busca pela longevidade está associada à meta de evitar a velhice. $\mathrm{O}$ acesso aos meios para isso podem indicar os fatores que serão determinantes da reorganização social e da distribuição de direitos, poder e prestígio. Onde a juventude é um valor, ter acesso aos meios de evitar o envelhecimento passa a ser um fator de distinção e de vida bem sucedida. 0 desafio está em controlar o envelhecimento naturalmente. 


\section{Referências}

BArros, M. L. (2004). "A velhice na contemporaneidade”. In: PEixoto, C. (org.). Família e Envelhecimento. Rio de Janeiro, FGV.

Boввіо, N. (1997). O tempo da memória. Rio de Janeiro, Elsevier.

BouRdiEu, P. (1983). "A juventude é apenas uma palavra". In: Questões de sociologia. Rio de Janeiro, Marco Zero.

DEBERT, G. (2006). "A antropologia e o estudo dos grupos e das categorias de idade". In: BarRos, M. L. (org.). Velhice ou terceira idade. Rio de Janeiro, FGV.

Elias, N. (2001). A solidão dos moribundos, seguido de, envelhecer e morrer. Rio de Janeiro, Jorge Zahar.

Featherstone, M.; Hepworth, M. (2000). "Envelhecimento, tecnologia e o curso da vida incorporado". In: DeBerT, G. (org.). Políticas do corpo e o curso da vida. São Paulo, Sumaré.

GoldenberG, M. (2007). O corpo como capital. Rio de Janeiro, Record.

Helal, R.; Coelho, M. C. (1996). "Mídia, idolatria e construção da imagem pública: um estudo de caso". Pesquisa de Campo. Rio de Janeiro, n. 3-4, p.79-88.

Kalache, A.; Veras, R. P.; Ramos, L. R. (1987). “O envelhecimento da população mundial: um desafio novo". Rev. Saúde Pública [online], vol. 21, n.3, p. 200-210. Disponível em: <www.scielo.br/scielo.php?script=sci_arttext\&pid=S0034$89101987000300005 \& \operatorname{lng}=$ pt\&nrm=iso>.

MotTA, A. B. (2006). “Chegando pra idade”. In: BARros, M. L. (org.). Velhice ou terceira idade. Rio de Janeiro, FGV.

OEPPEn, J.; VAuPEL, J. (2002). "Broken limits to life expectancy". Science, vol. 296, p. 1029-1031, maio.

PEIXoto, Clarice. (2004). "Entre o estigma e a compaixão e os termos classificatórios: velho, velhote, idoso, terceira idade...”. In: BARRos, M. L. (org.). Velhice ou terceira idade. Rio de Janeiro, FGV.

STUCCHI, D. (2006). "O curso da vida no contexto da lógica empresarial: juventude, maturidade e produtividade na definição da pré-aposentadoria". In: BARROS, M. L. (org.). Velhice ou terceira idade. Rio de Janeiro, FGV. 
TEIXEIRA, I. N. D. O.; NERI, A. L. (2008). "Envelhecimento bem-sucedido: uma meta no curso da vida". Psicol. USP [online], vol. 19, n. 1, p. 81-94. Disponível em: $\leq w w w . s c i e l o . b r /$ scielo.php?script=sci arttext\&pid=S010365642008000100010\&l $\underline{\text { ng}}=$ en\&nrm $=$ iso\&tlng $=$ pt $>$.

Recebido em março/2011

Aprovado em agosto/2011 